\title{
Develop models of anatomical studies using acrylic resin
}

\author{
CARVALHO, F. T. C. * , ROSSI JUNIOR, W. C. and ESTEVES, A. \\ Departamento de Anatomia, Instituto de Biociências, Universidade Federal de Alfenas - UNIFAL-MG, \\ Rua Gabriel Monteiro da Silva, 714, CEP 37130-000, Alfenas, MG, Brasil \\ *E-mail: faiscamg@hotmail.com
}

\begin{abstract}
Introduction: Many researchers among them Galen, Andreas Vesalius, Hippocrates, Leonardo Da Vinci, among others, have dedicated themselves to anatomical studies and methods of conservation bodies. Being Human Anatomy a basic content for all undergraduate courses involving health, their study is essential, as well as getting parts and cadavers for study. Faced with the difficulties encountered today, the search for alternative methods in teaching the human body has been incessant. Given a search for human anatomy to find a way of preserving anatomical specimens in the best possible way, new techniques have been described and studied over time laboratories. This work was performed in order to obtain a new technique for the study of anatomical parts by applying a fresh crystal acrylic resin, with low cost and the elimination of liquid preservatives, thus facilitating the handling of the parts. Material and Methods: Different anatomical parts, which were included in a block of ice were used; were cut from 4 to $6 \mathrm{~mm}$ and subjected to a battery of alcohol to rapid dehydration, then the pieces were embedded in acrylic resin Crislight ${ }^{\circledR}$ and then subjected to sanding and finishing, and polishing to obtain a good aesthetics and performance. Results: This study demonstrated that it is possible to include anatomical piece polyester resin, thereby obtaining a study model that offers excellent visibility, a technique easy to perform and affordable. Conclusion: But more studies should be conducted to improve the technique and develop models with better quality. Although the behavior of the resin due to different tissue types in a future study should be noted.
\end{abstract}

Keywords: resins, anatomy, polyester, models.

\section{Introduction}

Concern for conservation bodies in existence for over 5000 years. Several Chemicals, Doctors, Pharmacists, Alchemists, among others, tried to find techniques to conservation bodies. At first, the main reason was of a religious nature, however, later, scientific-academic nature.

Many scholars among them Galen, Andreas Vesalius, Hippocrates, Leonardo Da Vinci, among others, dedicated themselves to anatomical studies and bodies conservation methods.

Andreas Vesalius (1514-1564), flamenco anatomist, was among the first to systematize the anatomical dissection as a teaching method, which earned him the title of father of anatomy.

Later in the eighteenth century, Guillermo Hunter (1718-1783) used alcohol as a fixative and preservative (LAUTH, 1976). Pierrento Dionis tannic acid employed to prevent mold growth. Froncois Chaussier (1742-1828) employed the mercuric chloride to prevent decay and to promote mummification. Johann Jacob Ritter (1714-1784) used the arsenic. Carlo Giacomini (1840-1898) used the glycerin to preserve bodies, whose technique earned its name. Later in 1868, August Wilhem V. Hoffmann (1818-1892), he discovered and started using formaldehyde as substance to preserve corpses (PETRUCELLI, 1997).

Being Human Anatomy a basic science for all undergraduate programs involving health, it is essential its study in depth for subsequent applications in various specific clinical areas for each course.

Some of the preservation techniques used, such as formalinfixation is still quite controversial due to the use of formaldehyde, which is a toxic agent to living beings (GARDNER, 1971).

The conservation through Formaldehyde is the most used because of its low cost and rapid tissue penetration $(6 \mathrm{~mm}$ in twelve hours). However, as a counterpoint brings a strong odor, which irritates the mucous membranes and is a volatile and toxic product to humans still being classified as a carcinogen (HILDEBRAND, 1968). Furthermore, formolized parts are heavy and lose their coloration became darker with time. Since the glicerination, technique maintains the integrity of the pieces keeps the light and non-toxic and without the unpleasant odor of formolized like parts, but the technical costs four and a half times that of formaldehyde and leads fortnight for the impregnation of glycerin.

The acrylic resin has been used widely in the medical and dental field, as an alternative to replace or restore lost or damaged parts (GUBENER PLASTINATE GmbH, 2012).

They exist for the inclusion of some anatomical parts synthetic resins that are already used for some time for this purpose. These resins are often not found in the domestic market, which greatly increases the cost of the technique. Some of the resins found in the market are urea resin, Inclusion in Selectron, Inclusion in Methyl methacrylate, Inclusion in Polyester Resin, Resin Inclusion Canus C32, and Inclusion in Resiplast (WALTER, 2004).

This experiment will propose obtaining a new fixing technique of anatomical parts to cool, with the use of crystal acrylic resin.

The objective of this experiment is to develop a new technique for conservation and fixing of anatomical parts and obtain study models, which will primarily benefit, low 
cost and the elimination of liquids and toxic preservatives. The realization of this technique can therefore be applied as a new form of conservation and study of anatomical parts used in the anatomy laboratories of educational institutions, elementary, middle and higher.

\section{Material and Methods}

Cadaveric specimens were used already in the Department of Anatomy, UNIFAL -MG to the experiment. Initially they were not used human parts, the shortage of this type of material in the department (Figure 1).

Fresh pieces previously placed in a plastic vessel containing water without any fixative, so that they could subsequently be frozen at a temperature of $-15^{\circ} \mathrm{C}$, while a mold is obtained to be later subjected to the respective sections.

During the preparation of the anatomical part in an ice block, this piece must be positioned such that its extent in the focus block of ice in the center thereof, giving consistency and facilitating cutting at the saw. For this to be done needs to be done the ice pack in two (02) to center half and pack the part proposal at its center.

After the ice pack with the play properly positioned inside have been made, it was placed in its upper portion a transparency sheet with lines printed in the desired measures, becoming a guide to achieving the cuts, avoiding inaccuracy.

Specific gloves were used, with inner liner to hold the ice pack during the cuts and goggles as personal protective measure.

To achieve the cuts we used a tape-type saw with $0.5 \mathrm{~mm}$ thick and $1 \mathrm{~cm}$ in diameter (Starrett, São Paulo - SP, Brazil) (Figure 2). Each cut had obtained 3-5 millimeters thick, so that all anatomical details could be viewed with a good degree of accuracy.

After cutting, the pieces were placed in a plastic container to be subjected to dehydration in a battery ascending alcohols (70\%, 80\%, 90\% and absolute), 1 hour under each remaining alcohol.

Once dried, the pieces were included in acrylic resin. Some steps had to be respected so that they were successful in making the anatomic study models.

The container should be directly proportional to the size of the part to be included in the resin.

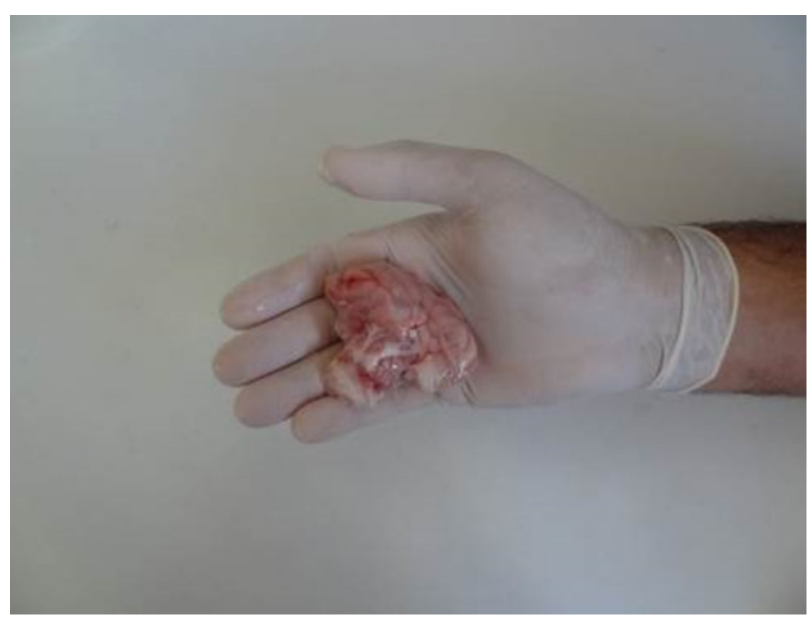

Figure 1. Natural piece with no advance fixing.
For the amount of resin used was verified the size of the piece and the action of the cuts and the size of container used. The resin would partly cover the container creating a first layer, in which the part would be superimposed. In sequence, a second layer was added covering the part and its total volume.

The resin used was Crislight ${ }^{\circledR}$ (Siquiplás, São Paulo - SP, Brazil) and the catalyst P-Mek (Siquiplás, São Paulo - SP, Brazil), in the ratio of 30 drops of catalyst per $100 \mathrm{ml}$ resin (indication manufacturer). This ratio was varied so that if testing the occurrence of improvement or worsening when in contact with the anatomical parts.

The resin was manipulated in a graduated Becker and a wooden spatula was used to blend according to the manufacturer's specification.

With the resin have manipulated added to the container first layer (proportional to the volume of the part). Waited for the period of initial polymerization of the resin, until it was at a gelatinous state, acquiring consistency for packaging part.

Subsequently, a further quantity of resin was manipulated in the same proportion of the first half, which was stored in the container covering the piece slowly until it was completely filled.

The final polymerization of the resin occurred in a container with water and ice so that the heat of reaction does not interfere with anatomical specimen (Figure 3 ). After the total period of polymerization, the piece was subjected to finishing and polishing.

The finish was carried out using a scribe to delimit the part edges and create a template of the final shape of the pieces. After being scratched, parts of the edges were cut in saw blade type, giving the desired contour in parts.

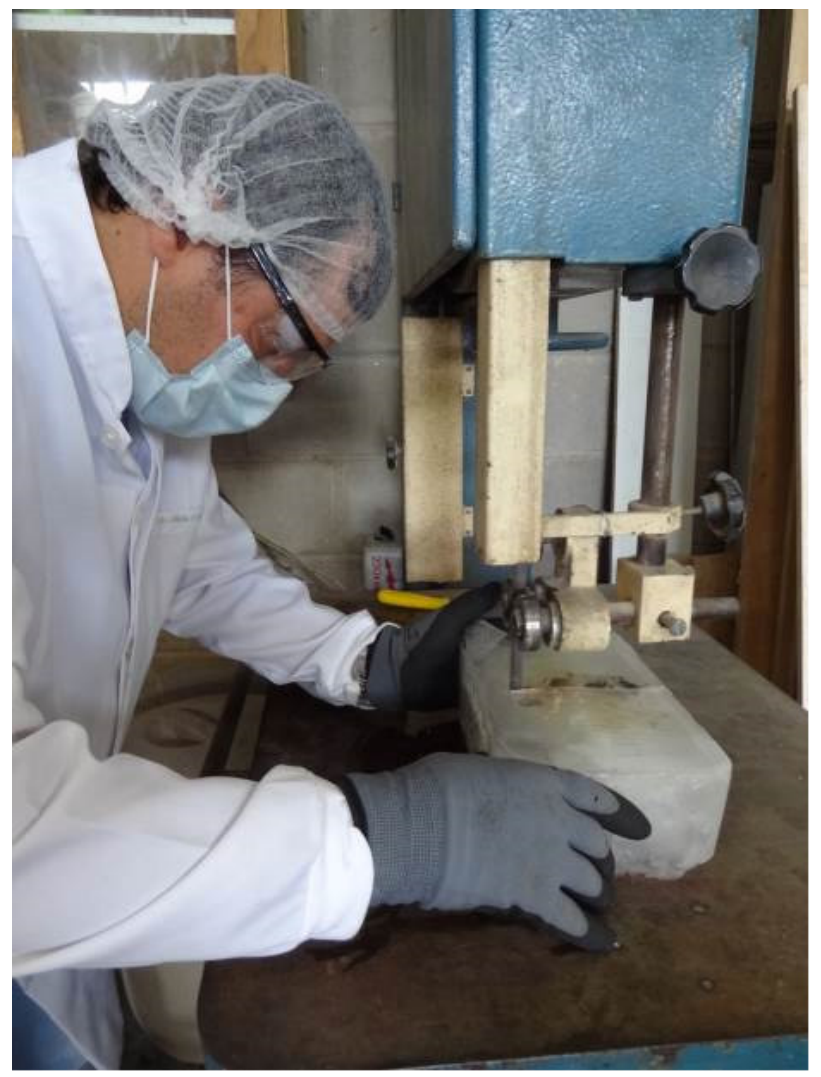

Figure 2. Saw used to cut the block of ice. 


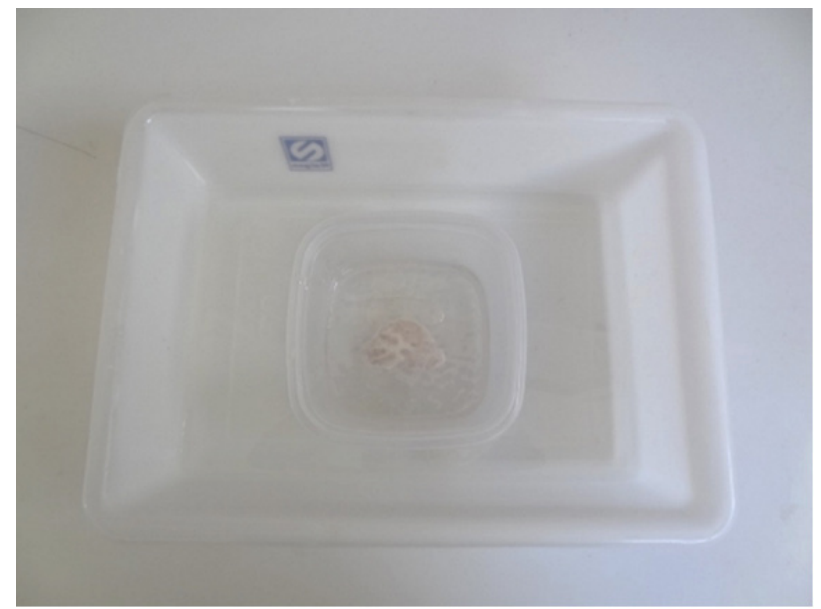

Figure 3. Box with the work piece placed in a container with ice water.

The pieces were sanded for better finishing with sandpaper in different grits (Norton, Sao Paulo - SP, Brazil), observing a sequence of thicker to thinner, being used the following grits: $100,220,400,600,1000$, removing the wrinkles and blemishes on the surface of the resin. This step can be performed using an electric sander Orbital or strap type (Skill 7649, São Paulo - SP, Brazil) to facilitate and accelerate the sanding. For completion of this stage were used sandpaper of water number 1200 (Figure 4).

Carried out the finishing step, the piece was polished. Initially it was used a cloth brush, number 10, with Pumice stone in a small around polishing. Every piece was polished, to observe the complete removal of scratches and imperfections on the surface of the resin and complete transparency.

The pre-polished piece was washed with running water. Then switched to brush around polishing (Schulz, Joinville SC, Brazil) with a flannel brush number 10:01 bat polishing Vipibril model (VIPI, Pirassununga - SP, Brazil) was used, pressing this bat on cloth brush, and then hold up the final polishing of the model, getting the brightness and end transparency. (Figure 5).

Finally, fashioned into a wooden case for packaging, protection and transport of parts. This case was made in the exact size of the sum of all the piece cuts.

\section{Results}

Through the experiment conducted, it was noted that it is possible to create new study models, meeting the basic requirements that have been proposed, such as low cost, easy to perform technique, good visibility and maintaining the anatomical aspect of the piece (Figure 6). The requirements were obtained successfully (Figures 7,8 ).

Because of the friability of acrylic resin, one should be careful when handling the piece, avoiding falls and shocks with high impact, which can lead to fractures and cracks on parts (Figure 9).

Note also that spaces not filled by the resin, imply the degradation of the piece, so the part must be completely filled and covered by the resin (Figure 10).

In the experiment, the initial phase of some aspects observed on the behavior of the front resin piece demonstrated that

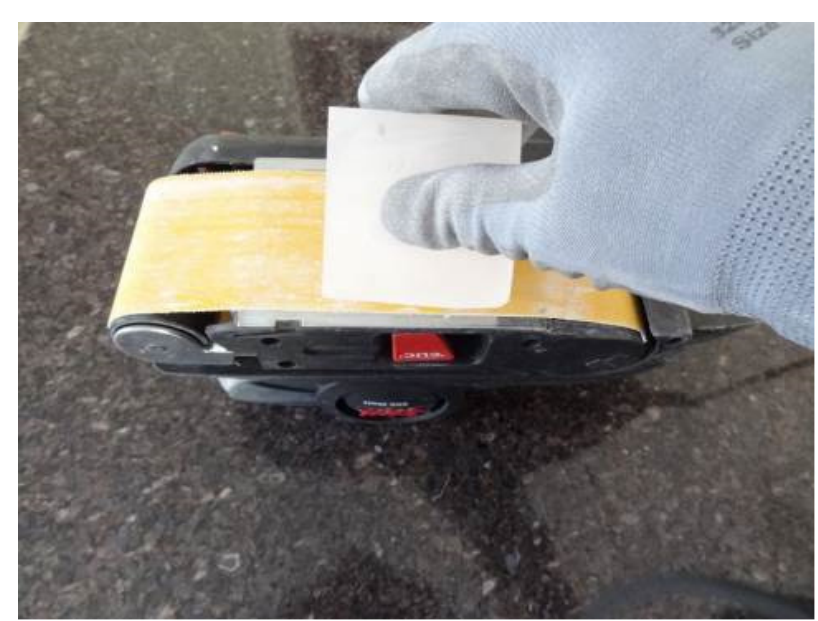

Figure 4. Piece being sanded belt sander (Skill 7640, São Paulo - SP, Brazil).

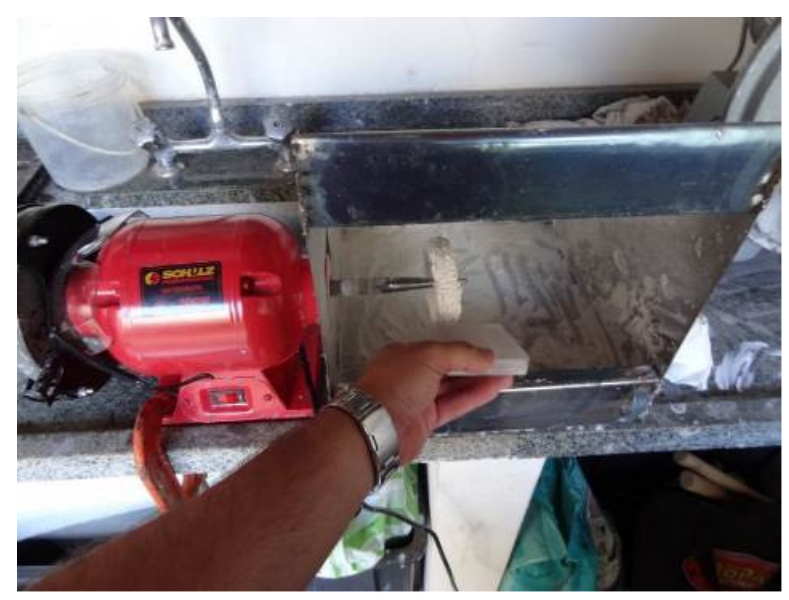

Figure 5. Piece receiving polishing with brush and Pumice stone.

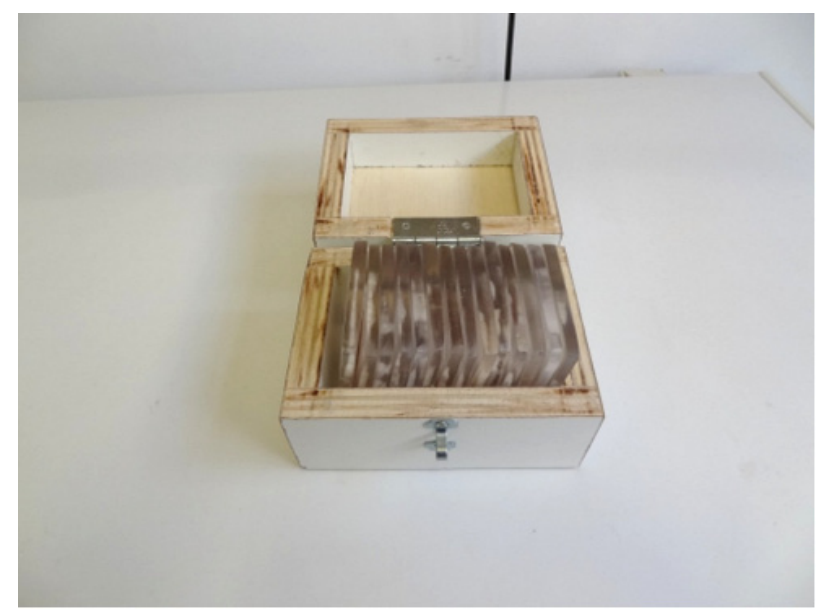

Figure 6. Case made for storing the pieces.

insulation used in an attempt to keep color in anatomical specimens left the piece with a whitish, making the visualization of anatomical structures of interest (Figure 11).

Yet at the initial stage it was observed that due to release of heat caused by the resin polymerization reaction was noted that the pieces suffered great influence of temperature, causing 


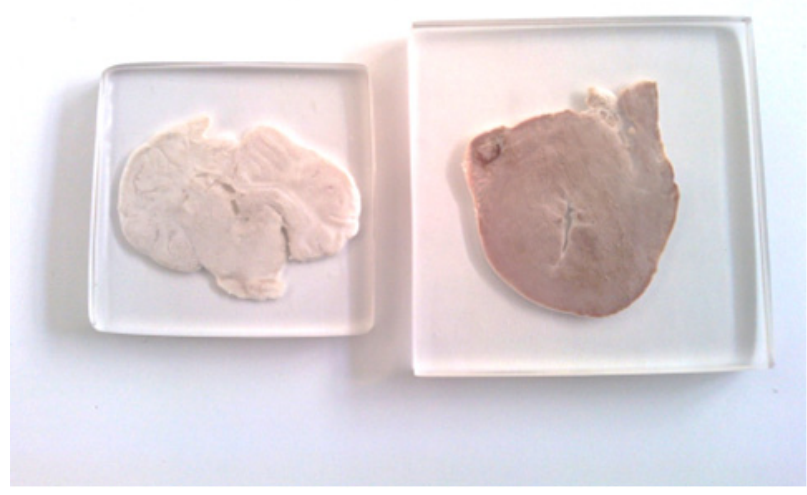

Figure 7. Final appearance of the parts after polishing.

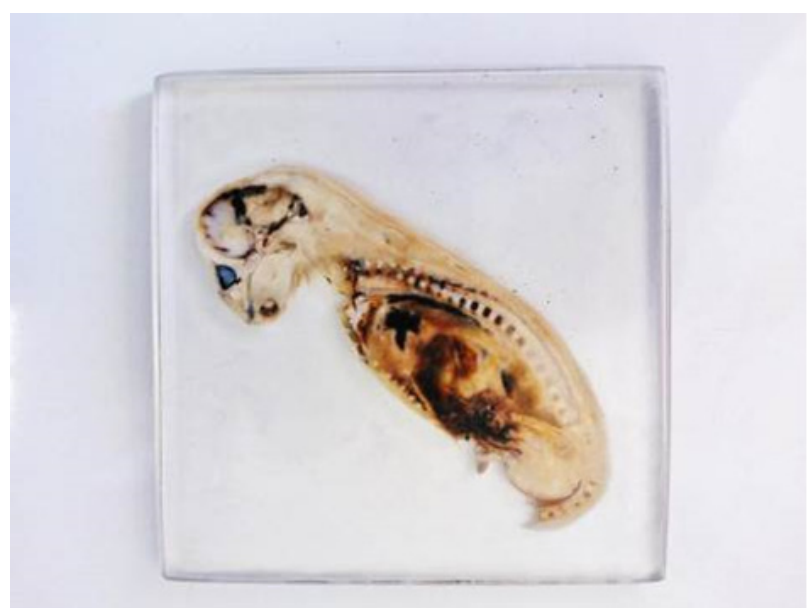

Figure 8. Other final result.

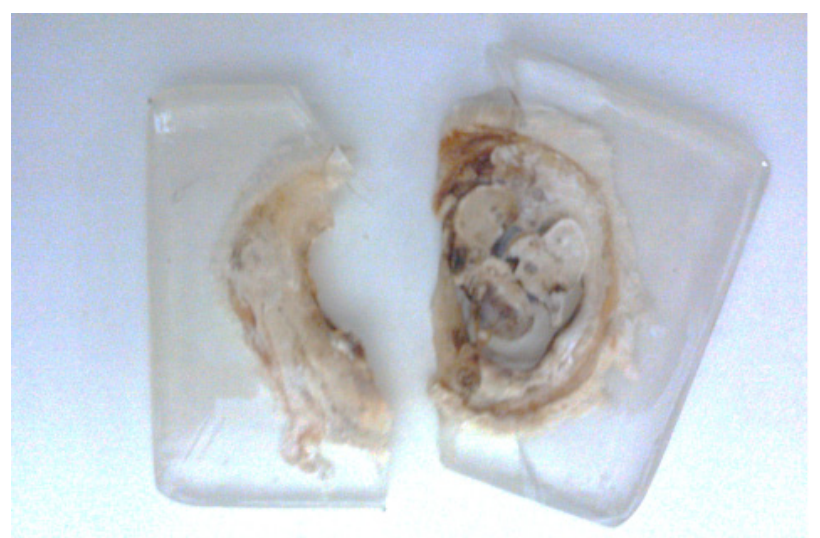

Figure 9. Piece fractured due to the fall.

some "cooking" of the part within the resin, as well as cracks and bubbles emerged the resin proportionally to the amount of resin and thus the size of the piece.

During the experiment, it is also noted that the use of the forms of acrylic polymethyl methacrylate suffered distortions,

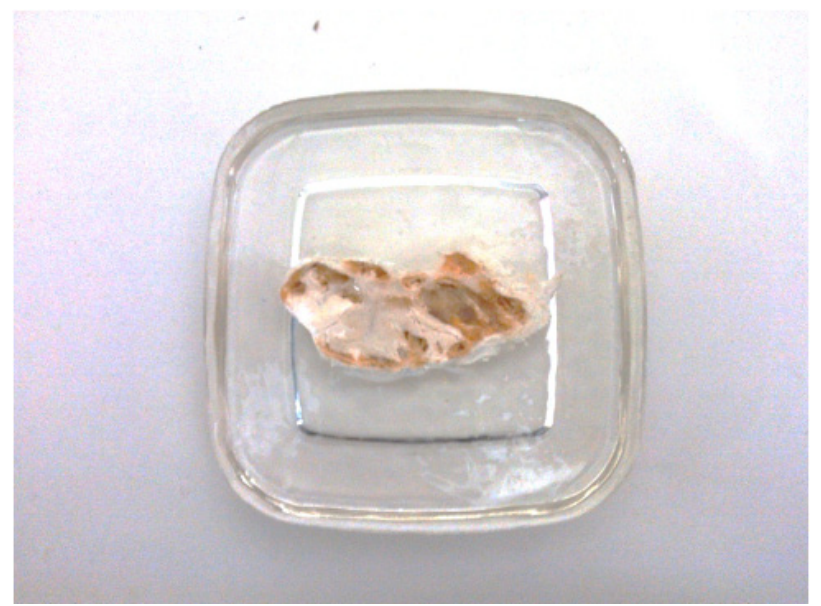

Figure 10. Part degraded due to the lack of resin.

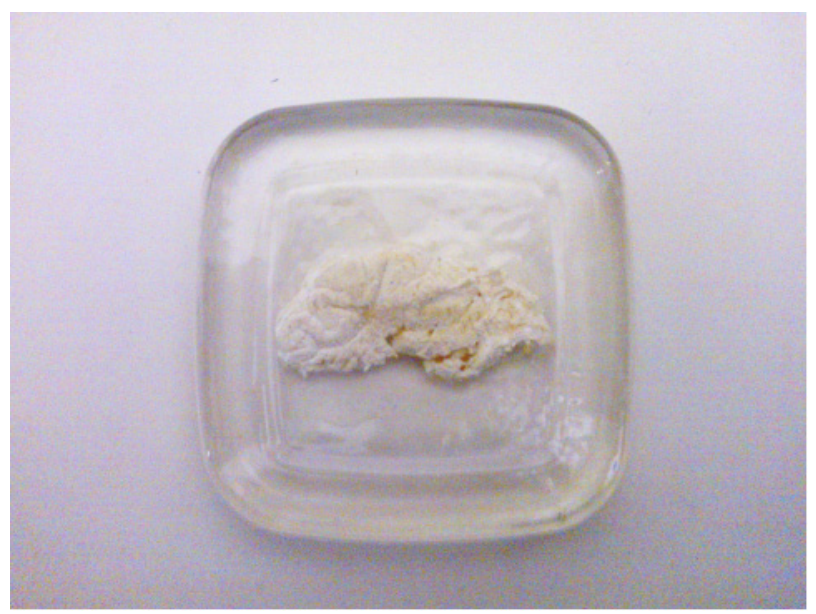

Figure 11. Whitish part with insulating usage.

cracks and merger with Crislight ${ }^{\circledR}$ resin, ruling out its use for the experiment.

The glass shapes showed good characteristics opposite to the resin, but there has been no method, which can be, performed the step of withdrawal or deflasking the resin inside, and beyond its cost is high.

\section{Conclusions}

This study demonstrated that it was possible to include anatomical piece in acrylic resin, thereby obtaining a study model that offers the following features:

a) Good degree of visualization of anatomical structures of the parts due to the great degree of transparency that the resin demonstrated;

b) Good durability of the part, since resin showed a good degree of resistance;

c) Low cost for technical execution, because the used materials possess a reduced price;

d) Because of acrylic resin used is crumbly piece becomes relatively weak to the falls, which may cause cracks and fractures; 
e) Held technique presented is easy to perform, which makes feasible its implementation in any educational institution;

f) In the face of other parts of preservation techniques, the proposed technique showed a disadvantage compared the glicerinação techniques and formalin fixation of large-sized parts such as members, since a large amount of resin required to cover large parts size;

g) For the polyester resins of the type used in prosthetics of techniques, the proposed technique offers advantages in terms of cost and a disadvantage in appearance of the parts;

h) The model study showed low polymerization shrinkage due to the use of ice containing box to slow the polymerization process;

i) It has been the model to date, about two years, demonstrates good durability without changes in characteristics.

\section{References}

GARDNER, E., GRAY, DJ. and O'RAHILLY, R. Anatomia humana. Rio de Janeiro: Guanabara-Koogan, 1971.

GUBENER PLASTINATE GmbH. Von Hagens products. Heideberg, 2010. Available from: <http://www.plastination-products.com/ media/download/Kata_Small_Kompl.pdf>.Access in: 04 Aug 2012.

HILDEBRAND, M. Anatomical preparation. Berkeley: University of California Press, 1968. 240 p.

LAUTH, GG. La Medicina en Granada desde su reconquista hasta nuestros dias: centros hospitalarios y facultades de medicina. Granada: Universidad de Granada, 1976. 59 p.

PETRUCELLI, LJ. História da Medicina. Editora Manole, 1997.

WALTER, T. Plastination for display: a new way to dispose of the dead. Journal of the Royal Anthropological Institute, 2004, vol. 10, n. 3, p. 603-627. http://dx.doi.org/10.1111/j.1467-9655.2004.00204.x.

Received August 25, 2015 Accepted November 11, 2016 